\title{
Interannual variability of Eastern China Summer Rainfall: the origins of the meridional triple and dipole modes
}

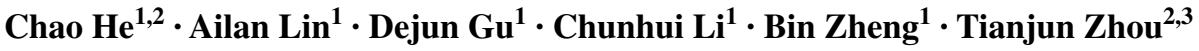

Received: 2 September 2015 / Accepted: 27 March 2016 / Published online: 9 April 2016

(C) The Author(s) 2016. This article is published with open access at Springerlink.com

\begin{abstract}
The Eastern China Summer Rainfall (ECSR) has a strong interannual variability, and the leading mode of interannual ECSR variability is characterized by either meridional triple or dipole structures as claimed by previous studies. In this study, decadal differences of the leading ECSR modes are investigated, using observational data and long-term integrations of climate models. Observational analyses show that the leading mode of ECSR is characterized by a meridional triple structure during 1979-1993 whereas a meridional dipole structure during 1994-2014. In the 200-year air-sea coupled simulation of Community Climate System Model version 4 (CCSM4), the leading mode of ECSR is characterized by triple structure in some decades whereas dipole structure in other decades, and decadal shifts between the triple and dipole structures are seen. In the 200-year simulation of the stand-alone atmospheric component of CCSM4 (i.e., CAM4) forced by fixed SST annual cycle, the triple mode and dipole mode are also identified, suggesting both of these two modes and their decadal shift can be generated by atmospheric internal dynamics without air-sea interaction. As agreed by observation, CCSM4 and CAM4 simulations, the positive
\end{abstract}

Chao He

hechao@mail.iap.ac.cn

Tianjun Zhou

zhoutj@lasg.iap.ac.cn

1 Institute of Tropical and Marine Meteorology (ITMM), China Meteorological Administration (CMA), Guangzhou, China

2 LASG, Institute of Atmospheric Physics (IAP), Chinese Academy of Sciences (CAS), Beijing, China

3 Joint Center for Global Change Studies (JCGCS), Beijing, China (negative) phase of the triple leading mode is associated with enhanced (weakened) western north Pacific subtropical high, southward (northward) shifted East Asian jet, and meridional wave train along the East Asian coast. The positive (negative) phase of the dipole leading mode is associated with enhanced (weakened) western north Pacific subtropical high, enhanced (weakened) East Asian jet, and zonal wave train over mid-latitude Eurasian continent.

Keywords Eastern China Summer Rainfall · Interannual variability $\cdot$ Leading mode $\cdot$ Air-sea interaction

\section{Introduction}

Eastern China is the most densely populated region and the most important agricultural region of China. Regulated by East Asian monsoon, Eastern China receives the largest fraction of annual rainfall in summer (Wu et al. 2003). The Eastern China Summer Rainfall (ECSR) is characterized by strong interannual variability, which may arise from the strong interannual variability of the western North Pacific subtropical high (WNPSH) (Lu 2001; Sui et al. 2007; Wu and Zhou 2008). The interannual variability of ECSR leads to floods in some areas but droughts in some other areas of Eastern China, and it greatly affects the agricultural production and economic activities of China. Great efforts have been devoted to studying the mechanism for the interannual ECSR variability (e.g., Lu 2005; Huang et al. 2011, 2014; Ma et al. 2011).

The interannual variability of ECSR is usually characterized by meridional rainfall anomaly pattern. Empirical Orthogonal Function (EOF) analyses were widely used to extract the leading modes of interannual ECSR variability (Chen et al. 2006; Han and Zhang 2009; Ye and Lu 2012). 
Many studies revealed that the leading mode of interannual ECSR variability is characterized by a meridional triple structure, i.e., excessive rainfall along the Yangtze River accompanied by deficient rainfall over South China and North China, and vice versa (Ding et al. 2008; Huang et al. 2012; Day et al. 2015; Sun and Wang 2015). In contrast, some other studies argued that the meridional dipole pattern is also an important mode, i.e., excessive rainfall over south of Yangtze River accompanied by deficient rainfall north of the Yangtze River, and vice versa (Ding et al. 2008; Han and Zhang 2009). The formation of the meridional triple and dipole modes is explained by the interannual variability of Sea Surface Temperature (SST) anomalies (Wu et al. 2003; Hsu and Lin 2007; Han and Zhang 2009), especially the El Nino-Southern Oscillation (ENSO) (Wu et al. 2003; Feng et al. 2011; Li et al. 2014).

The leading mode of ECSR is an important benchmark for seasonal rainfall prediction (Ai et al. 2008; Pang et al. 2014). However, the pattern of the leading mode is not stable with time and may suffer to decadal changes (Ye and Lu 2012; Sun and Wang 2015). Although the decadal changes in the mean state of ECSR have been well documented (e.g., Gong and Ho 2002; Ding et al. 2008, 2009; Zhao et al. 2011), little attention was paid on the decadal difference of the interannual ECSR mode. It was reported that the leading modes of ECSR differ in different decades (Ye and Lu 2012; Sun and Wang 2015). However, it is still unclear whether the decadal difference of the leading mode originates from the air-sea coupled system or atmospheric internal noise.

Observational records may be too short to document decadal climate variability. In this study, we use the outputs of Community Climate System Model version 4 (CCSM4) and its atmospheric component, i.e., Community Atmospheric Model version 4 (CAM4). This model has been widely used by previous studies and it performs reasonably well in the simulation of ENSO (Chen et al. 2013; Krishnamurthy and Krishnamurthy 2014) and Asian monsoon (Sperber et al. 2013; He and Zhou 2014; Song and Zhou 2014). The climate variability in CCSM4 with constant external forcing (greenhouse gases, aerosols, etc.) originates from the air-sea coupled system, whereas the climate variability in CAM4 forced by fixed SST originates from the atmospheric internal dynamics. Based on observation and model outputs, the current study focuses on the following questions: (1) Are there any decadal changes in the leading ECSR mode in recent decades? (2) What are the leading ECSR modes in CCSM4 and CAM4? Is there any decadal shift in the leading mode between triple pattern and dipole pattern in CCSM4 and in CAM4?

The rest of this article is organized as follows. The data, model and methods are introduced in Sect. 2. The observed decadal difference in the leading mode within 1979-2014 is addressed in Sect. 3. Extended analyses using the long term control simulation of CCSM4 and CAM4 are documented in Sects. 4 and 5, respectively. Finally, the major findings in this study are summarized in Sect. 6.

\section{Data, model and methods}

In the observational analysis in Sect. 3, the following observation (including reanalysis) data spanning the period of 1979-2014 are adopted: (1) Global Precipitation Climatology Project (GPCP) monthly precipitation (Adler et al. 2003). (2) Monthly geopotential height, vertical velocity and wind from National Centers for Environmental Prediction-Department of Energy AMIP-II reanalysis (NCEP2) (Kanamitsu et al. 2002). (3) Extended Reconstruction SST (ERSST) version $3 b$ (Smith et al. 2008). We focus on the seasonal mean precipitation of June-July-August (JJA) over Eastern China $\left(20^{\circ}-43^{\circ} \mathrm{N}, 107^{\circ}-122^{\circ} \mathrm{E}\right)$.

The pre-industrial control run of CCSM4 is downloaded from Coupled Model Inter-comparison Project Phase 5 (Taylor et al. 2012), to save the computational cost. The pre-industrial control run of CCSM4 spans 500 years, and only the last 200 years are selected for analyses in this paper to keep the figures clear and readable. The first 300 years are also analyzed, and the results are consistent with the last 200 years. The long-term control simulation helps us to extend the observational analyses, and it also helps to investigate whether the internal variability of the air-sea coupled system could generate decadal shifts of the leading ECSR mode.

In order to investigate the interannual mode originating from atmospheric internal dynamics, we had run an experiment using CAM4 (the atmospheric component of CCSM4), which is forced by the climatological annual cycle of SST derived from the last 200 years in the preindustrial control simulation of CCSM4. The CAM4 simulation is performed under a finite volume dynamic core. It has 26 vertical hybrid sigma-pressure levels and a horizontal resolution of $0.9^{\circ}$ in latitude and $1.25^{\circ}$ in longitude, which is the same as the CCSM4 simulation. The radiative forcing (e.g., greenhouse gases, aerosols) are set fixed at the pre-industrial level, which is the same as the CCSM4 simulation. The CAM4 simulation was run for 203 years and the last 200 years are selected for analyses.

To focus on the interannual variability, an 8-year highpass filter is applied on the year-by-year time series before further analyses. In order to reveal the changes of the leading interannual mode, the 15-year running EOF analysis is applied to the zonal averaged precipitation of Eastern China $\left(107^{\circ}-122^{\circ} \mathrm{E}\right.$ averaged), and the time-latitude profile of the first running EOF mode is obtained. The EOF decomposition on the zonal averaged precipitation over Eastern China 
is reasonable, since seasonal rainfall anomalies over Eastern China is dominated by east-west elongated belts (Han and Zhang 2009; Day et al. 2015). According to the running EOF analyses, typical epochs with different leading modes are identified, and further analyses are done on these epochs, respectively.

Traditional EOF analyses are performed separately on the standardized precipitation anomalies for different epochs with different leading modes, and the time series of the first principle component (PC1) are obtained. Composite analyses are performed on the circulation and SST anomalies, for the years with the PC1 value exceeding \pm 0.5 standard deviation. The composite analyses are performed for the positive and negative phases respectively, to pay attention to possible asymmetry (Hsu and Lin 2007). The statistical significance in the composite map is determined by Students' $t$ test at the $90 \%$ confidence level.

\section{Decadal shift of the leading ECSR mode in observation}

As shown in the running EOF pattern (Fig. 1a), the leading mode of the zonal mean rainfall is characterized by a meridional triple structure before the early 1990s, whereas a meridional dipole structure after the early 1990s. This decadal shift occurred around 1993/94. The running EOF mode of the vertical velocity is also characterized by a shift from a triple pattern into a dipole pattern in the 1990s (contours in Fig. 1a), which resembles that of rainfall. Based on the differentiated leading mode of ECSR, we call the period of 1979-1993 as Triple epoch and 1994-2014 as Dipole epoch in this section. To validate the results based on running EOF analysis, conventional EOF analyses on precipitation are performed for the Triple and Dipole epochs respectively, and the results are shown in Fig. 2.

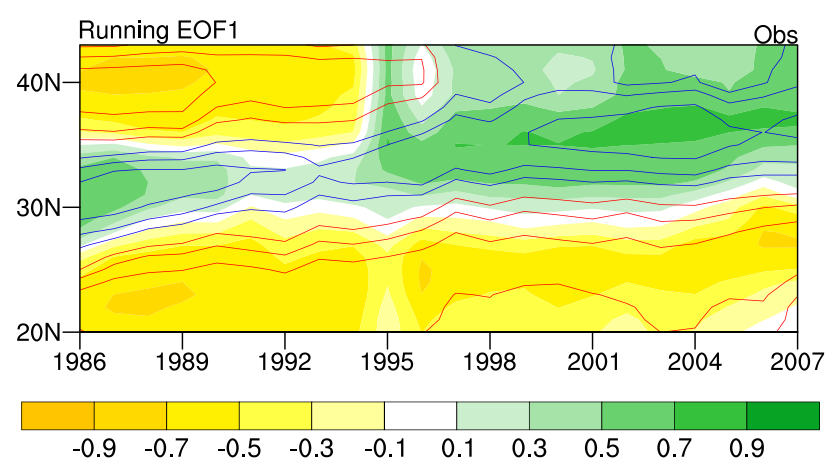

Fig. 1 The time-latitude profile for the 15-year running EOF mode on the zonal $\left(107^{\circ}-122^{\circ} \mathrm{E}\right)$ averaged rainfall (shading) and $500 \mathrm{hPa}$ vertical velocity (contours) over Eastern China. The contour interval is $0.2 \mathrm{~Pa} / \mathrm{s}$ and the positive (negative) contours are in red (blue)
During Triple epoch, the leading mode is characterized by triple structure, with a positive anomaly located along the Yangtze River at about $30^{\circ} \mathrm{N}$, sandwiched by negative anomalies at North China and South China (Fig. 1a). This triple pattern explains $30.9 \%$ of the total variance, and it closely resembles the spatial pattern shown by some previous studies (Fig. 1 in Hsu and Lin 2007; Fig. $2 \mathrm{f}$ in Sun and Wang 2015). In contrast to Triple epoch, the leading EOF mode for the Dipole epoch is characterized by a meridional dipole structure (Fig. 2d), with negative anomaly south of Yangtze River and positive anomaly north of Yangtze River. This dipole pattern explains $27.8 \%$ of the total variance, and it resembles the pattern shown by Han and Zhang (2009) (their Fig. 1a) and Huang et al. (2011) (their Fig. 2a).

How about the higher order modes for the two epochs? The second and the third modes for Triple epoch are characterized by noisy spatial patterns, which resembles neither a triple nor a dipole pattern (Fig. 2b, c). The second mode for Dipole epoch is characterized by a meridional triple pattern (Fig. 2e), indicating the triple mode does not disappear but became less important in Dipole epoch. The third mode during Dipole epoch is also noisy (Fig. 2f).

Previous studies claimed that the East Asia-West Pacific climate experienced a decadal change in many aspects
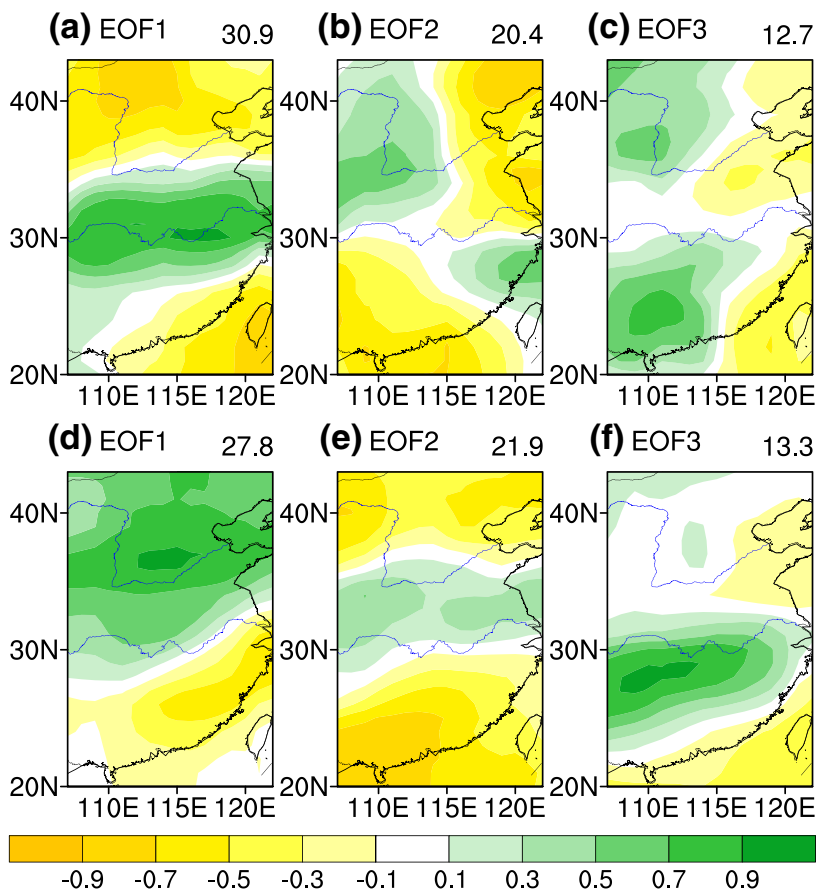

Fig. 2 The spatial patterns for EOF modes of interannual rainfall variability. a-c The first three EOF modes for the triple epoch (19791993). d-f The first three EOF modes for the dipole epoch (19942014). The percentage of variance (unit: \%) explained by each mode is marked on the upper-right corner of each panel 

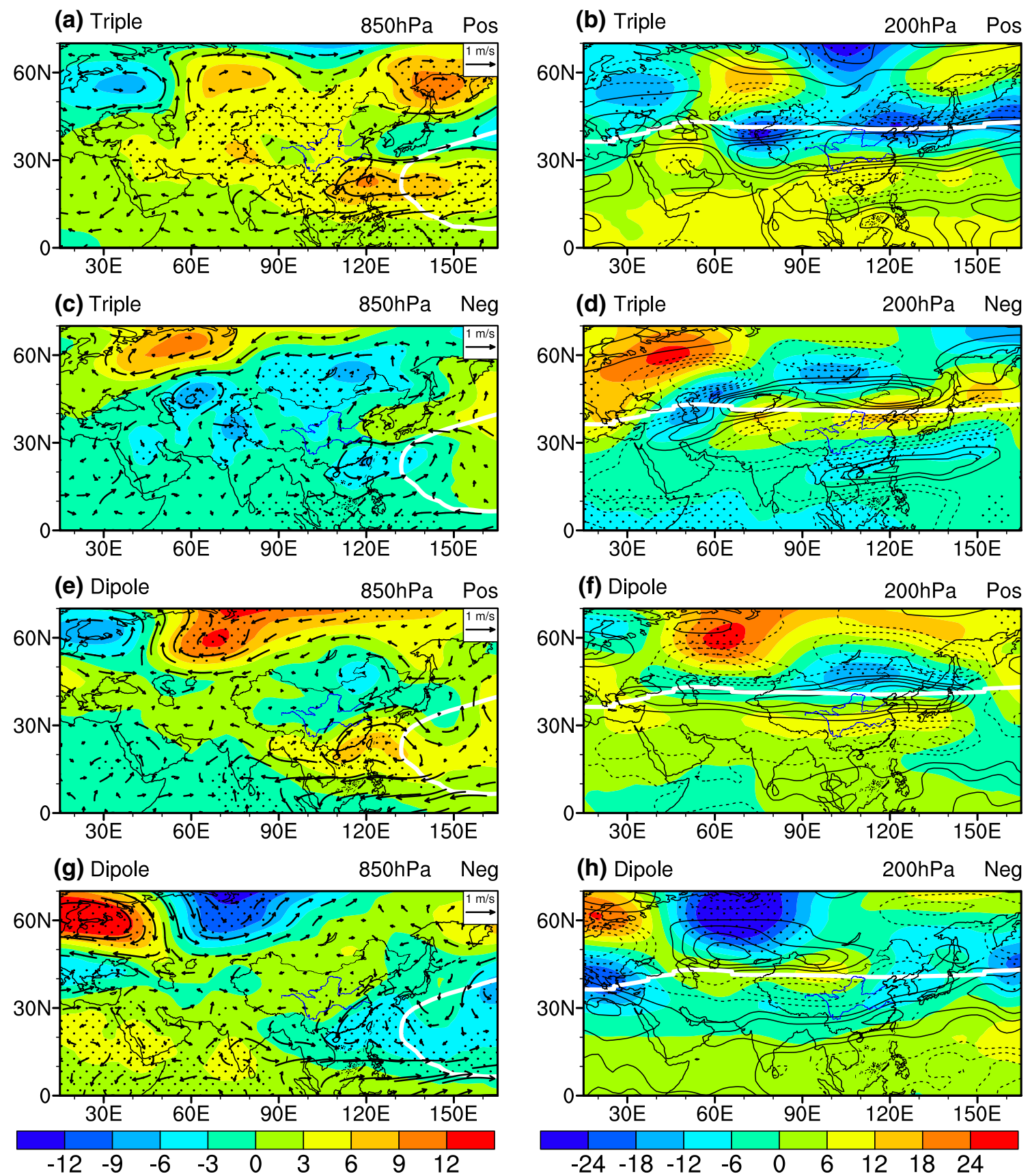

Fig. 3 The composite circulation anomalies at $850 \mathrm{hPa}$ (left column) and $200 \mathrm{hPa}$ (right column) associated with the leading EOF modes for the two epochs. a-d The positive and negative phases of the leading mode for triple epoch. e-h same as a-d but for dipole epoch. The shading is the geopotential height, and the composite geopotential

height statistically significant at the $90 \%$ confidence level is stippled. The vectors are $850 \mathrm{hPa}$ wind, and the contours are the $200 \mathrm{hPa}$ zonal wind (contour interval is $0.5 \mathrm{~m} / \mathrm{s}$, positive/negative contours are in solid/dashed lines). The white lines indicate the climatological location of WNPSH (left panel) and the jet axis (right panel)

around 1993/94 (Wu et al. 2010a; Chen et al. 2012; Kajikawa and Wang 2012; Chen and Zhou 2014). Therefore, the decadal shift in the leading mode seems to be one facet the large-scale phenomenon. To investigate the largescale atmospheric and oceanic anomalies associated with the leading mode in the Triple and Dipole epochs, the composite circulation anomalies at 850 and $200 \mathrm{hPa}$ are shown in Fig. 3, and the composite SST anomalies at JJA and its monthly evolution are shown in Fig. 4.

During the positive phase of Triple epoch, an anomalous anticyclone at $850 \mathrm{hPa}$ is located at the southeastern coast of China (Fig. 3a), indicating an enhanced WNPSH. 
Fig. 4 The composite anomalies of SST associated with the leading EOF modes for the two epochs. The left panel is the simultaneous SST anomalies in $\mathrm{JJA}$, and the right panel is the composite monthly evolution of SST anomalies along the equator $\left(5^{\circ} \mathrm{S}-5^{\circ} \mathrm{N}\right.$ averaged $)$. The composite SST anomalies exceeding the $90 \%$ confidence level are stippled
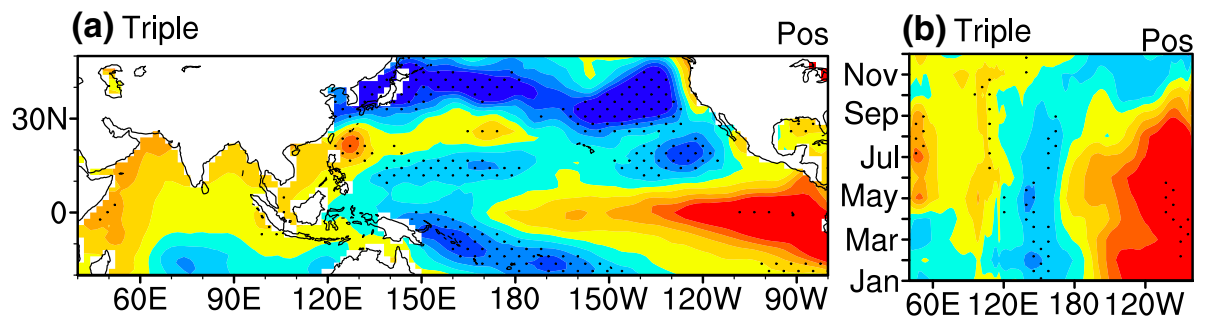

(c) Triple

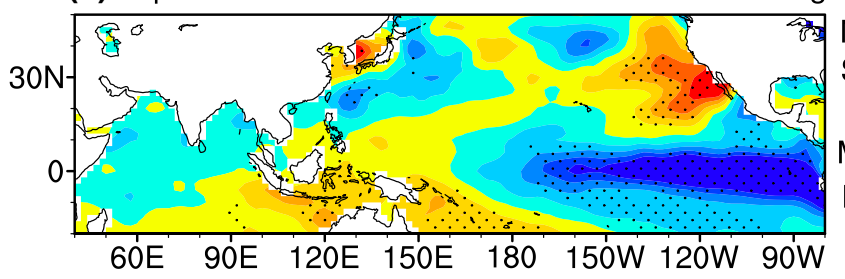

(d) Triple

Neg

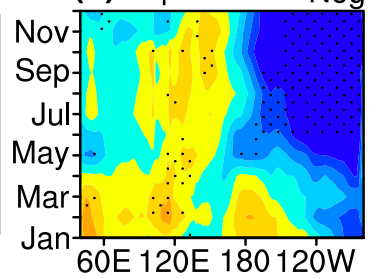

(e) Dipole

Pos

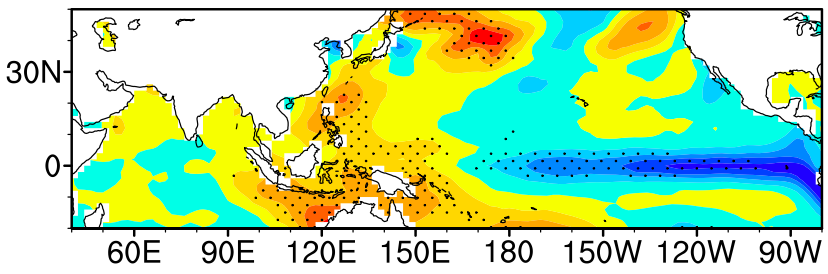

(f) Dipole

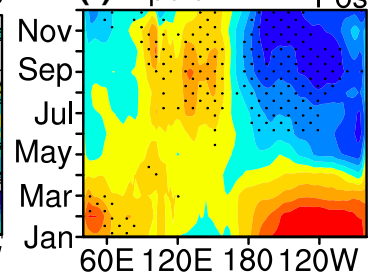

(g) Dipole

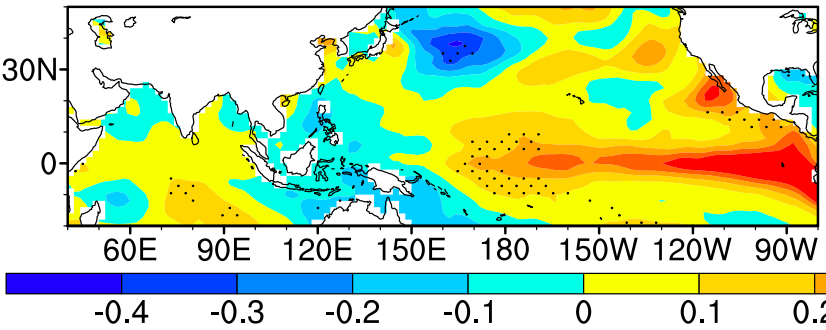

Neg

(h) Dipole

Neg

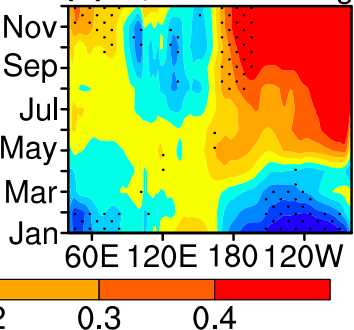

On one hand, the enhanced WNPSH is responsible for the deficient rainfall over South China. On the other hand, it contributes to the excessive rainfall along Yangtze River by anomalous northward water vapor transport on its western flank (Zhou and Yu 2005; Li et al. 2014). The enhanced WNPSH is a part of a meridional wave train, with anticyclone-cyclone-anticyclone anomalies from south to north along the East Asian coast (Fig. 3a). This meridional wavetrain resembles the Pacific-Japan or East Asia-Pacific (PJ/ EAP) teleconnection (Nitta 1987; Huang and Sun 1992). At $200 \mathrm{hPa}$ (Fig. 3b), the composite zonal wind anomalies are characterized by enhanced (weakened) westerly wind on the southern (northern) flank of the jet axis, indicating a southward shift of East Asian Jet (EAJ). The southward shift of EAJ favors abundant rainfall along the Yangtze River valley and deficient rainfall over North China (Kuang and Zhang 2006; Ma et al. 2011; Li and Zhang 2014).

During the negative phase of the leading mode for the Triple epoch, the circulation anomalies are generally the opposite to the positive phase. The $850 \mathrm{hPa}$ circulation anomalies are characterized by weakened WNPSH, associated with a meridional wave train of cyclone-anticyclone-cyclone anomalies from south to north along the East Asian coast (Fig. 3c). The composite circulation anomalies at $850 \mathrm{hPa}$ for the negative phase is generally weaker than the positive phase, suggesting the asymmetry between the positive and negative phases. The $200 \mathrm{hPa}$ circulation anomalies are characterized by northward displaced westerly jet (Fig. 3d).

During the positive phase of Dipole epoch, an anomalous anticyclone is also seen over subtropical WNP (Fig. 3e), indicating an enhanced WNPSH. The enhanced WNPSH is responsible for the deficient rainfall south of Yangtze River and the excessive rainfall on its north. In contrast to the positive phase of Triple epoch (Fig. 3a), the meridional wave pattern along the East Asian coast is absent during Dipole epoch (Fig. 3e, f). At both $850 \mathrm{hPa}$ and $200 \mathrm{hPa}$, an anticyclone anomaly appears at about $60^{\circ} \mathrm{E}$ near the Ural mountain, suggesting stronger activity of the Ural blocking high (Gao et al. 2015). The anticyclone anomaly over Ural mountain is sandwiched by two cyclone anomalies located over Europe and northeastern China (Fig. 3e, f). The zonal 
wave train pattern may be responsible for the cyclonic anomaly over northeastern China and excessive rainfall over North China. At the same time, anomalous westerly wind is seen along the westerly jet, indicating an enhanced EAJ (Fig. 3f).

During the negative phase of Dipole epoch, the circulation anomalies are generally asymmetric about the positive phase. The WNPSH is weaker than normal (Fig. 3g). A barotropic cyclone is seen around Ural mountain, sandwiched by anticyclone anomalies over Europe and northeastern China (Fig. 3g). Westerly wind anomaly is seen along the jet axis and the EAJ is weaker than normal condition (Fig. 3h).

The positive phase of the triple leading mode is associated with positive SST anomaly over equatorial centraleastern Pacific and tropical Indian Ocean, and negative SST anomaly along equatorial western Pacific (Fig. 4a). This SST pattern is associated with decaying El Nino in previous winter (Fig. 4b). The positive SST anomaly over TIO is a response to El Nino during its decay phase (Lau and Nath 2003; Du et al. 2009; Xie et al. 2009), and it acts as a capacitor which prolongs the impact of decaying El Nino on WNP climate ( $\mathrm{Li}$ et al. 2008; Xie et al. 2009; Wu et al. 2010b). During the negative phase of Triple epoch, negative SSTA is seen over equatorial central-eastern Pacific and tropical Indian Ocean (Fig. 4c), associated with La Nina condition throughout the year (Fig. 4d).

The positive phase of the dipole leading mode is associated with negative SST anomalies over equatorial centraleastern Pacific, and positive SST anomalies around the maritime continent (Fig. 4e), corresponding to developing La Nina (Fig. 4f). The enhanced WPNSH can be forced by either the positive SST anomalies over the maritime continent (Sui et al. 2007; Chung et al. 2011) or the negative SST anomalies over equatorial central Pacific (Wang et al. 2013; Chen et al. 2015; He et al. 2015). The SST anomalies for the negative phase of the dipole leading mode are generally opposite to the positive phase (Fig. 4g), corresponding to developing El Nino (Fig. 4h). Compared with the positive phase, the composite SST anomalies for the negative phase are weaker and marginally significant, suggesting asymmetric nature of the dipole leading mode.

Based on the above observational analyses, the leading ECSR mode changed from meridional triple structure to meridional dipole structure in the early 1990s. Decadal climate changes in East Asia may be caused by many factors, such as anthropogenic greenhouse gas and aerosol forcing (Jiang and Tian 2013; Guo et al. 2013; He and Zhou 2015), decadal variability of the air-sea coupled system (Kajikawa and Wang 2012; Wu et al. 2016), and atmospheric internal dynamics such as mid-latitude wave train $(\mathrm{Wu}$ 2002; Wu and Wang 2002) and atmospheric blocking (Gao et al. 2015). It is hard to find out the accurate cause for the decadal change of leading ECSR mode in the early 1990s. However, by extending the observation with long-term integration of air-sea coupled model and its atmospheric component model, it is possible to investigate whether these two leading modes could originate from the air-sea coupled system and pure atmospheric internal dynamics. In the next section, we extend our analyses by using the long-term coupled simulation of CCSM4.

\section{Leading mode of interannual ECSR variability in CCSM4}

The above observational analyses suggest that the circulation and SST anomalies for the two leading modes are different. It seems that both the triple and dipole modes are coupled with SST. However, the observational record within 1979-2014 seems too short to exclude the possible impact of other external factors, such as anthropogenic greenhouse gases and aerosols. The long term integration of CCSM4 under constant external forcing may provide additional evidences to consolidate our results based on observation. In this section, the following questions will be addressed: What is the leading mode in the air-sea coupled CCSM4 simulation with fixed external forcing? Is there any decadal shift in the leading mode between the triple and dipole patterns? Are the associated circulation and SST anomalies similar to those in the observation?

The running EOF analyses suggest that there are generally two types of leading modes, i.e., meridional dipole structure and triple structure (Fig. 5). These two types of leading modes shift from one to another every several decades, and the decadal changes similar to the 1993/94 decadal change in the observation can be identified. The leading modes for the periods of 7-18, 40-67, 158-167 are characterized by typical triple pattern, and they are joined

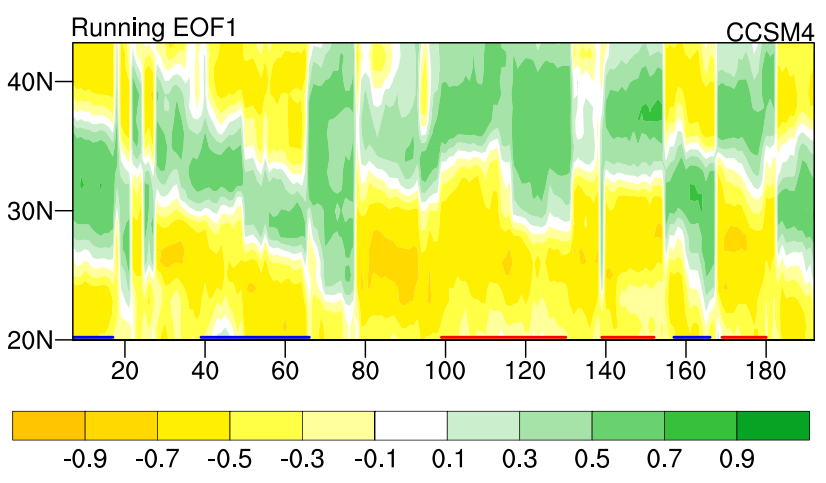

Fig. 5 a The time-latitude profile for the 15-year running EOF mode of zonal averaged $\left(107^{\circ}-122^{\circ}\right.$ averaged) summer rainfall in the 200 year freely-coupled CCSM4 simulation. The intervals marked by blue (red) lines are the selected periods with typical triple (dipole) leading mode 


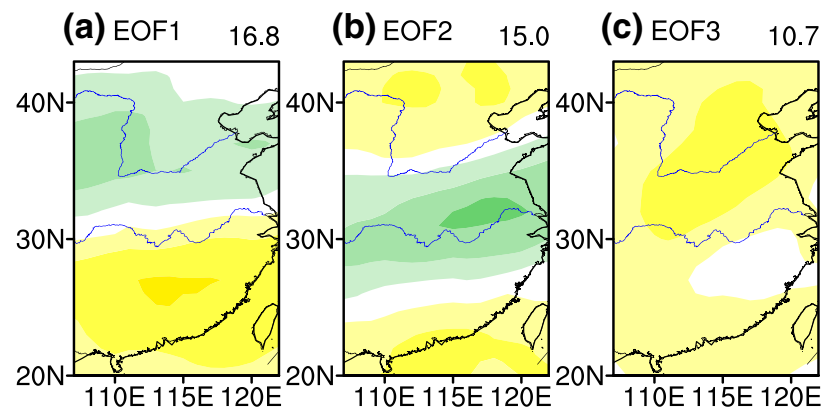

(d) EOF1 22.6
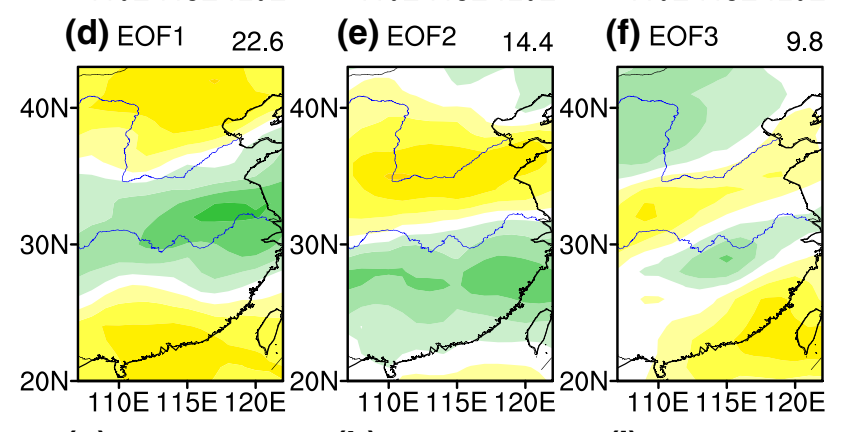

(g) EOF1

(h) EOF2

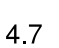

(i) EOF3 $\quad 11.5$

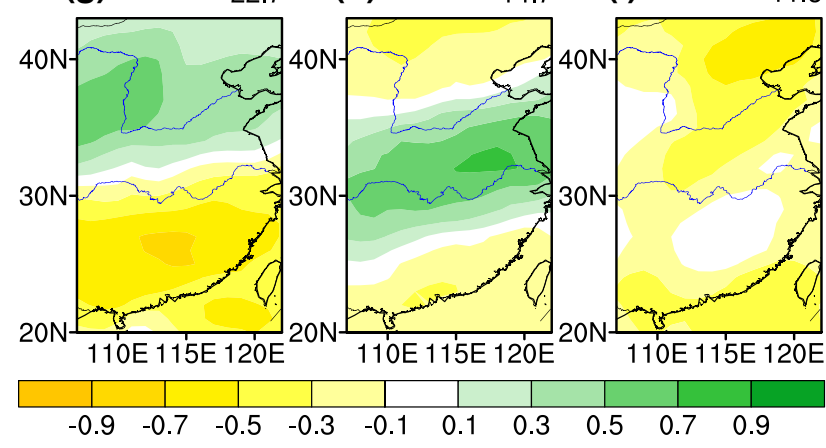

Fig. 6 a-c The first three EOF modes for the entire 200-year CCSM4 simulation. d-f The first three EOF modes for the triple epoch marked with blue lines in Fig. 5. g-i The first three EOF modes for the dipole epoch marked with red lines in Fig. 5. The percentage of variance (unit: \%) explained by each mode is marked on the upperright corner of each panel

together and referred to as Triple epoch in the following discussion of this section. The leading modes for the periods of 100-131, 140-153, and 170-181 are characterized by typical dipole pattern, and they are joined together and referred to as Dipole epoch in this section.

The first three EOF modes for CCSM4 simulation are shown in Fig. 6. For the entire 200-year period, the first EOF mode is characterized by a meridional dipole pattern, which explains $16.8 \%$ of the total variance (Fig. 6a). The second EOF mode is characterized by a meridional triple pattern and explains $15.0 \%$ variance (Fig. $6 \mathrm{~b}$ ). The third EOF mode is characterized by a monopole pattern and explains $10.7 \%$ variance (Fig. 6c). During Triple epoch, the triple leading mode explains $22.6 \%$ of the total variance (Fig. 6d). The second mode is a meridional dipole mode and explains $14.4 \%$ variance (Fig. 6e). The third mode shows a noisy spatial pattern and it explains $9.8 \%$ variance (Fig. 6f). During the Dipole epoch, the dipole leading mode explains $22.7 \%$ of the total variance (Fig. $6 \mathrm{~g}$ ). The second mode is a meridional triple mode and explains $14.7 \%$ variance. The third mode is a monopole mode and explains $11.5 \%$ variance. In CCSM4 simulation, the dipole (triple) mode does not disappear in the Triple (Dipole) epoch, but become the second mode and explains less variance than the leading mode.

Are the circulation and SST anomalies associated with these two leading modes in CCSM4 similar to those in observation? To answer this question, the composite circulation anomalies at $850 \mathrm{hPa}$ and $200 \mathrm{hPa}$ are shown in Fig. 7, for the positive and negative phases of the Triple epoch and the Dipole epoch of CCSM4, respectively. The composite SST anomalies for JJA and the monthly evolution of equatorial SSTA are shown in Fig. 8.

During the positive phase of Triple epoch (Fig. 7a), an anomalous anticyclone is located on the southeastern coast of China, indicating an enhanced WNPSH. The enhanced WNPSH is responsible for the deficient rainfall over South China and the excessive rainfall along the Yangtze River. The enhanced WNPSH is accompanied by an anomalous cyclone over the Japan Sea, resembling a PJ/EAP pattern. The $200 \mathrm{hPa}$ zonal wind is characterized by easterly (westerly) wind anomaly on the northern (southern) flank of jet axis (Fig. 7b), indicating a southward shifted EAJ. During the negative phase of Triple epoch, the circulation anomalies are opposite to the positive phase. The weakened WNPSH is also accompanied by meridional wave train along East Asian coast (Fig. 7c), and the EAJ is displaced northward (Fig. 7d). Therefore, the triple leading modes in observation and CCSM4 are controlled by similar circulation anomalies.

During the positive phase of Dipole epoch, anomalous anticyclone is also seen at the southeastern coast of China, indicating an enhanced WNPSH (Fig. 7e). But there is no meridional PJ/EAP pattern along East Asian coast. An anomalous high pressure is seen over Ural mountain at about $60^{\circ} \mathrm{E}$, accompanied by an anomalous low pressure over northeastern China (Fig. 7e). This zonal wave pattern within $40^{\circ}-50^{\circ} \mathrm{N}$ is more evident at $200 \mathrm{hPa}$ (Fig. 7f). At $200 \mathrm{hPa}$, westerly wind anomaly is seen along the jet axis, suggesting an enhanced EAJ (Fig. 7f). During the negative phase of Dipole epoch, the anomalous circulations are generally the opposite to the positive phase despite of marginal statistic significance, suggesting the asymmetry in the dipole mode. But the weakened WNPSH at $850 \mathrm{hPa}$ and the weakened EAJ at $200 \mathrm{hPa}$ are also evident (Fig. $7 \mathrm{~g}$, h). In all, the circulation anomalies associated with the dipole leading mode of CCSM4 are also similar to those in observation.

The composite SST anomalies for the leading modes in CCSM4 are also similar to the observation. During the 

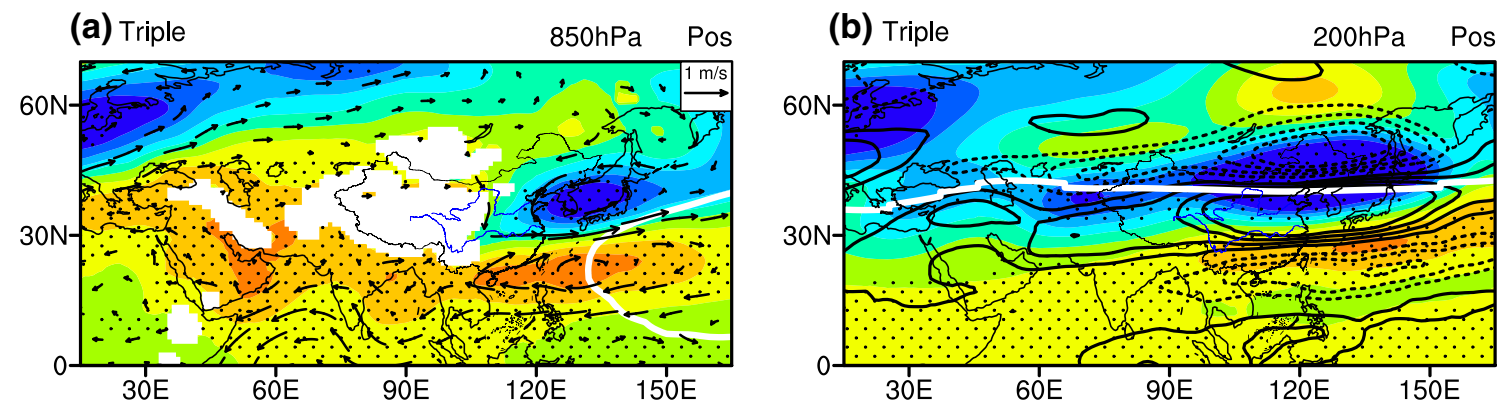

(c) Triple

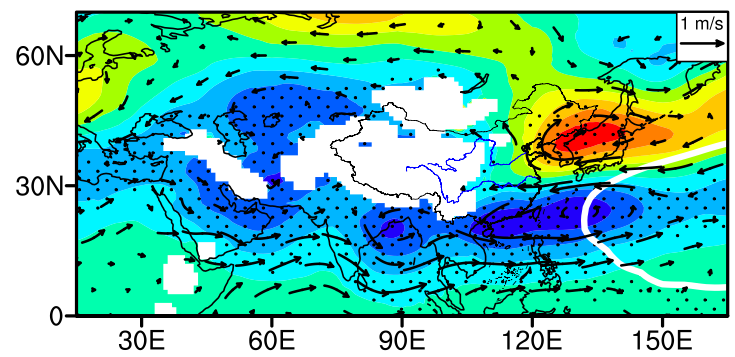

(e) Dipole

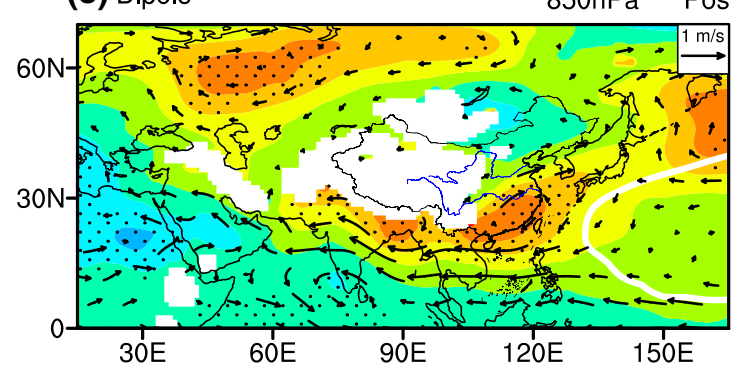

(g) Dipole

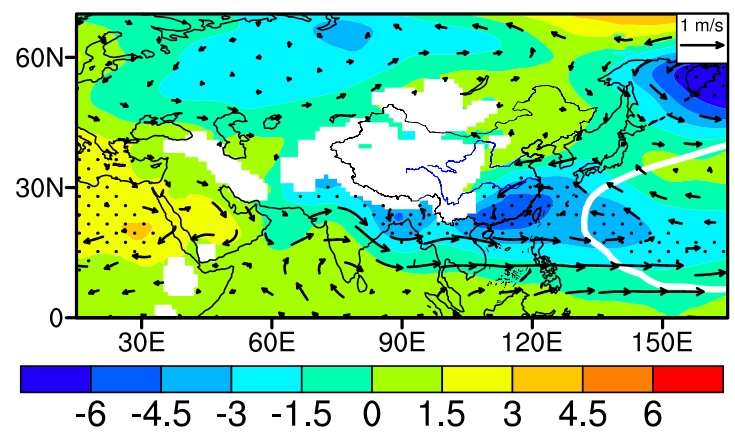

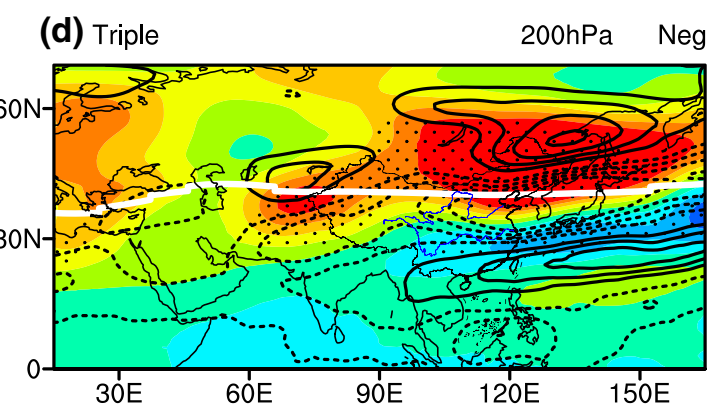

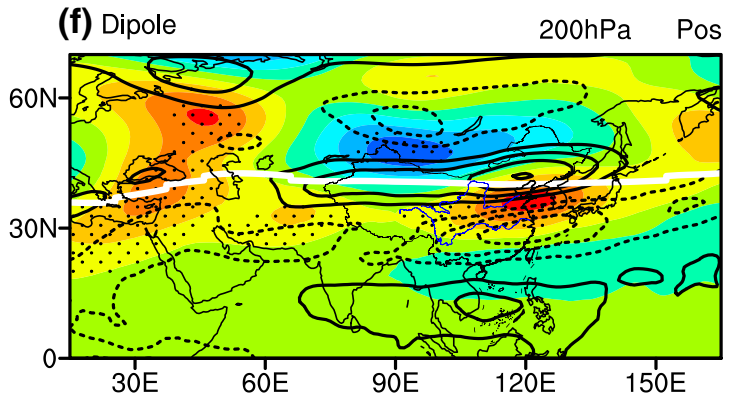

(h) Dipole

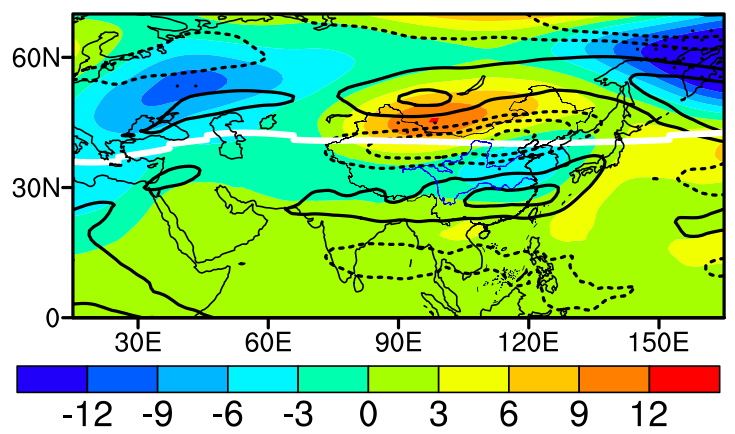

Fig. 7 Same as Fig. 3 but for the positive and negative phases of the dipole and triple epochs in CCSM4

positive phase of Triple epoch, the SST anomalies are positive over tropical Indian Ocean and equatorial central-eastern Pacific (Fig. 8a), associated with decaying El Nino from preceding winter (Fig. 8b). During the negative phase of Triple epoch, the SST anomalies are negative over tropical Indian Ocean and equatorial central-eastern Pacific (Fig. 8c), associated with decaying La Nina in previous winter despite of marginal statistic significance (Fig. 8d). During the positive phase of Dipole epoch, the SST anomalies are negative over equatorial central-eastern Pacific but positive around the maritime continent (Fig. 8e), accompanied by developing La Nina (Fig. 8f). During the negative phase of Dipole epoch, the SST anomalies are positive over equatorial central-eastern Pacific but negative around the maritime continent despite of marginal statistic significance (Fig. 8g), accompanied by developing El Nino (Fig. 8h). Generally, the simultaneous tropical SST anomalies for the triple and dipole leading modes are similar between observation and CCSM4. The association to ENSO phases are also similar between CCSM4 and observation, despite of small difference for the triple leading mode. 
Fig. 8 Same as Fig. 4 but for the triple and dipole epochs in CCSM4
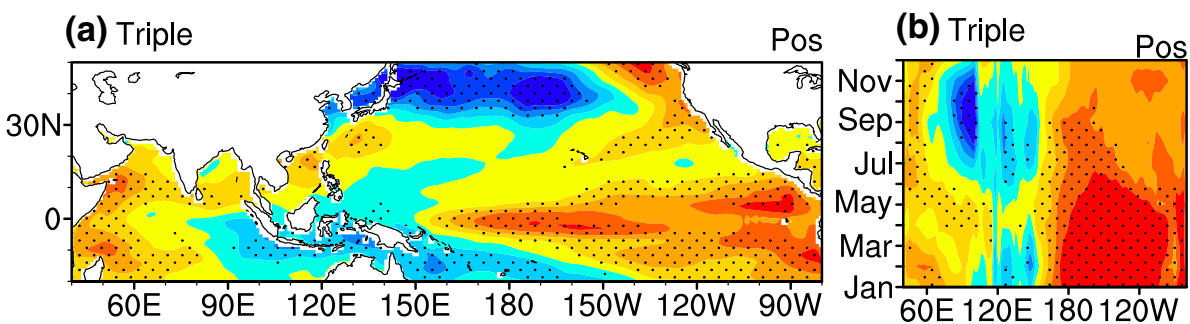

(c) Triple

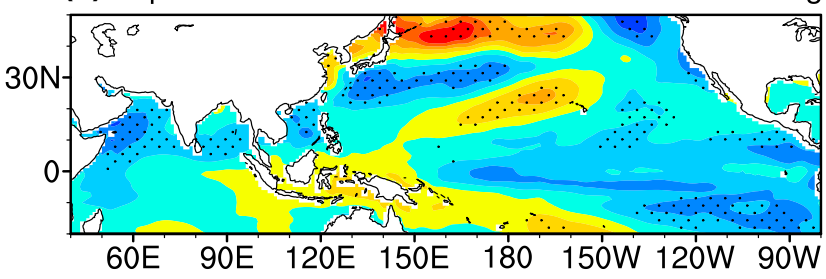

Neg

(d) Triple

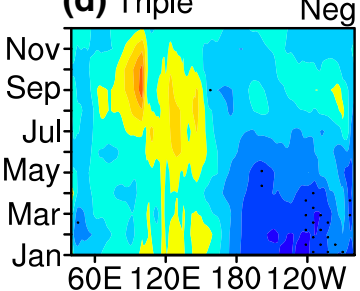

(e) Dipole

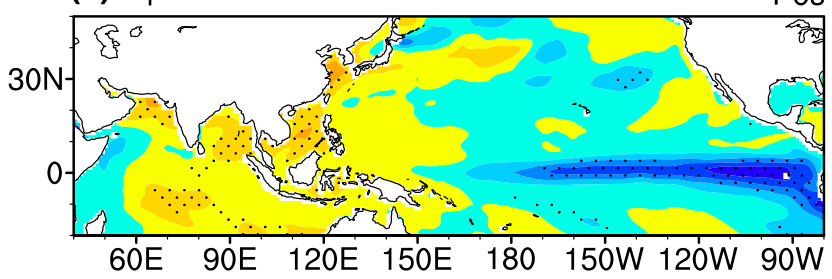

(f) Dipole

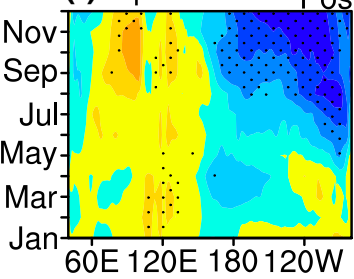

(g) Dipole

Neg

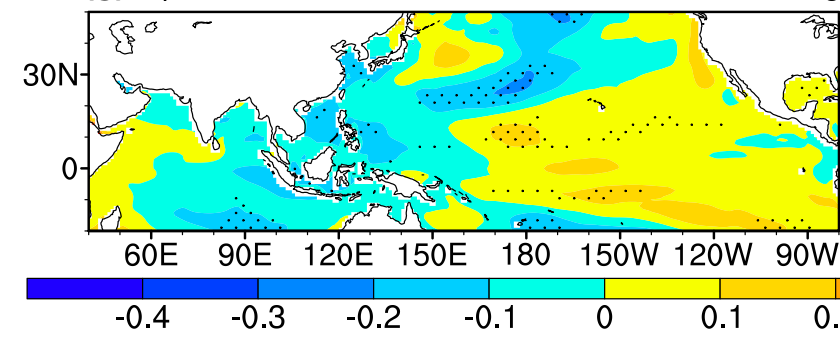

(h) Dipole

Neg

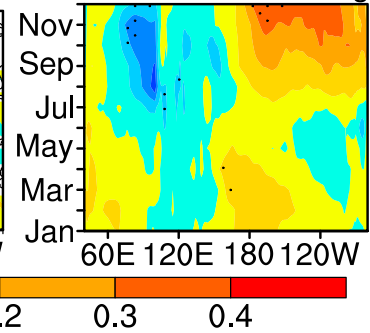

In all, both the triple mode and dipole mode can be simulated by CCSM4, and the decadal shifts of the leading mode between triple pattern and dipole pattern are also captured in CCSM4 with fixed external forcing. The circulation and SST anomalies associated with the leading modes in CCSM4 are similar to those in observation, for both the triple and the dipole leading modes. These evidences suggest that the both the triple leading mode and the dipole leading mode can originate from the air-sea coupled system, and the decadal shift in the leading mode between the triple pattern and dipole pattern can be generated by the intrinsic variability of the air-sea coupled system.

\section{Leading mode of interannual ECSR variability in CAM4}

What does the leading mode of ECSR look like if the SST is kept fixed? Is there any decadal shift in the leading mode between the triple and dipole patterns if there is no air-sea interaction? If there is, are the associated circulation anomalies similar to the air-sea coupled simulation? To document these questions, the 15-year running EOF mode for the 200-year simulation of CAM4 forced by fixed SST annual cycle is shown in Fig. 9. It is clear that the dipole pattern is the leading mode for most epochs, but the triple pattern is seen after the model year of 168 . Decadal shift of the leading mode from dipole to triple pattern exists in CAM4 simulation (around the year 167), although the frequency of such shift is much lower than CCSM4 simulation. In this section, the period of $168-193$ is referred to as Triple epoch, and the period of $8-163$ is referred to as Dipole epoch.

The first three EOF modes for the entire 200-year simulation of CAM4 are shown in Fig. 10a-c. The leading EOF mode is characterized by a meridional dipole pattern. The second mode is characterized by non-typical triple pattern and the third mode is characterized by non-typical monopole pattern. During the Triple epoch (Fig. 10d-f), the leading triple mode explains $32.6 \%$ of the total variance. 


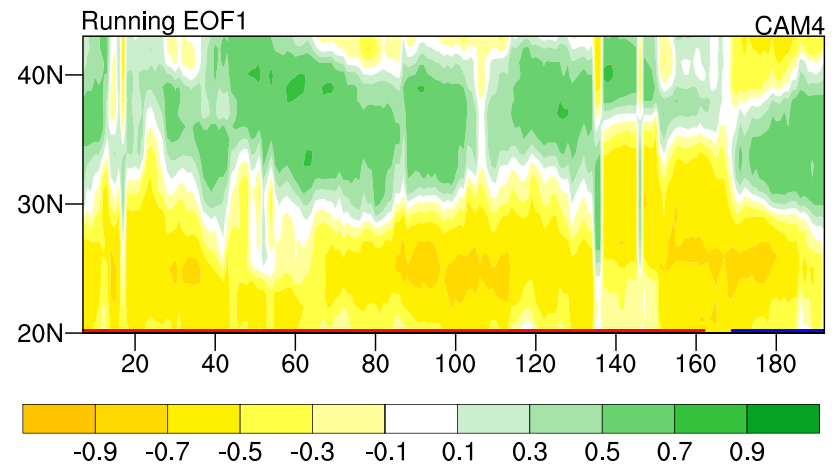

Fig. 9 Same as Fig. 5 but for the 200-year simulation of CAM4 forced by fixed SST

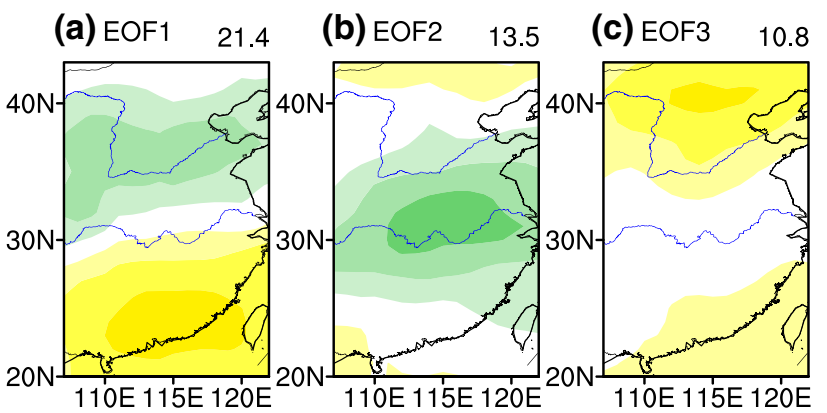
(d) EOF1
(e) EOF2
(f) EOF3 $\quad 12.0$

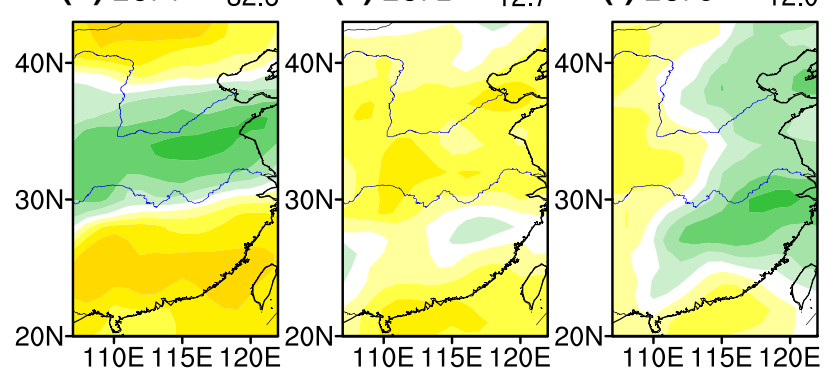

(g) EOF1 21.7

(h) EOF2 14.2

(i) EOF3 $\quad 10.0$

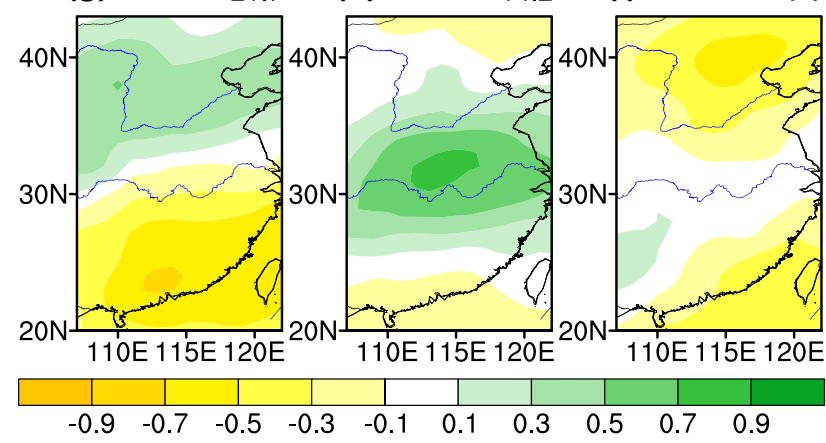

Fig. 10 Same as Fig. 6 but for the 200-year output of CAM4 (a-c) and its triple epoch $(\mathbf{d}-\mathbf{f})$ and dipole epoch $(\mathbf{g}-\mathbf{i})$

The second mode is a monopole mode and the third mode is characterized by east-west see-saw pattern. During the Dipole epoch (Fig. 10g-i), the leading dipole mode explains $21.7 \%$ of the total variance, the second mode is a non-typical triple mode and the third mode is a non-typical monopole mode. In the CAM4 simulation without air-sea interaction, the percentages of variance explained by the leading modes are close to those in CCSM4 simulation.

The anomalous circulations associated with the leading mode of CAM4 are shown in Fig. 11. During the positive phase of Triple epoch, there is an anomalous anticyclone on the southeastern coast of China, indicating an enhanced WNPSH (Fig. 11a). A meridional wave train is seen along the East Asian coast, reminiscent the PJ/EAP pattern. At $200 \mathrm{hPa}$, the westerly jet is displaced southward from Eastern China to Japan (Fig. 11b). During the negative phase of the Triple epoch, the large scale circulation anomalies are opposite to the positive phase, including the weakened WNPSH (Fig. 11c) and northward shifted jet EAJ (Fig. 11d). The meridional cyclone-anticyclonecyclone wave train is also seen along the East Asian coast (Fig. 11c).

During the positive phase of Dipole epoch, an anomalous anticyclone at $850 \mathrm{hPa}$ is seen at the southeastern coast of China, but no PJ/EAP pattern is seen (Fig. 11e), which resembles the positive phase of Dipole epochs in observation and CCSM4. A zonal wave train is composed by the anomalous high pressure system at the Ural mountain at $60^{\circ} \mathrm{E}$ and the low pressure system over northeast Asia (Fig. 11e). This zonal wave train pattern is more evident at $200 \mathrm{hPa}$ (Fig. 11f). During the negative phase of Dipole epoch, the WNPSH and the EAJ are both weaker than normal, and the mid-latitudinal zonal wave train is also seen (Fig. 11g, h). Compared with the positive phase, the anomalous circulation is weaker and shows weaker statistic significance, consistent with the asymmetry of the dipole leading mode in observation and CCSM4.

Based on the above results, the triple mode and the dipole mode are also the leading mode of ECSR in CAM4, and the decadal shift of the leading mode between the triple pattern and the dipole pattern is also seen in CAM4. The circulation anomalies associated with the triple and the dipole leading modes in CAM4 resemble those in observation and CCSM4, corroborating the similar atmospheric origins of triple and dipole modes in coupled and un-coupled systems. These evidences suggest that both the triple and dipole modes can originate from the atmospheric internal dynamics without air-sea coupling.

\section{Conclusion and discussion}

The ECSR is characterized by strong interannual variability. The triple mode and the dipole mode are both important components of interannual ECSR variability. Using observational data and simulations by air-sea coupled model 

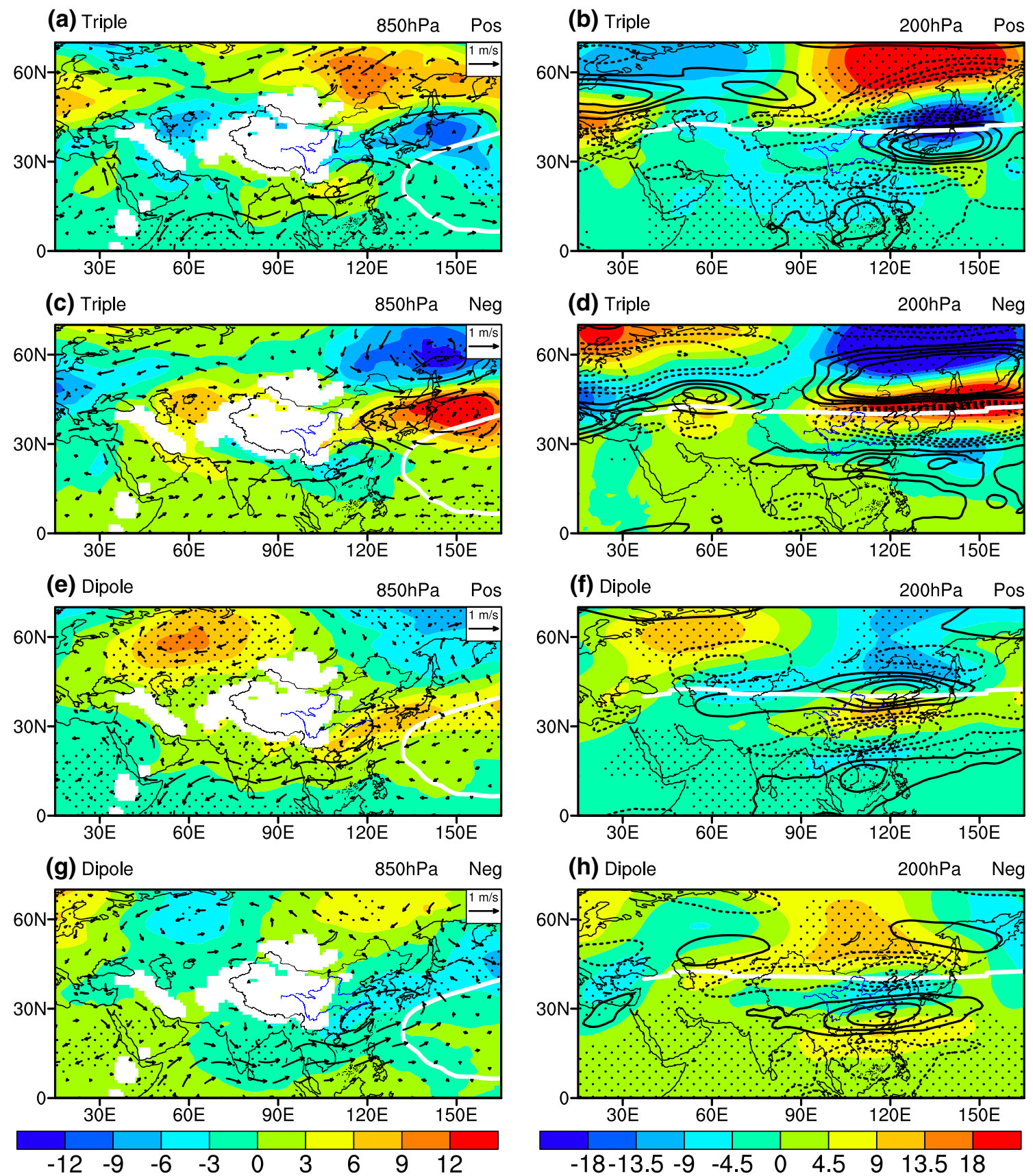

Fig. 11 Same as Fig. 8 but for the triple and dipole epochs of CAM4 simulation

and stand-alone atmospheric model, the leading mode of the interannual ECSR variability was investigated. Attention was paid on the decadal difference in the spatial structure of the leading mode and the associated circulation and SST anomalies. The main conclusions are summarized as follows.

1. The leading mode of the interannual ECSR variability has experienced a decadal shift in the early 1990s. The leading mode of ECSR for the 1979-1993 epoch is characterized by a meridional triple structure, the positive phase of which is associated with positive rainfall anomaly along Yangtze River and negative rainfall anomalies over North China and South China. In contrast, the leading mode of ECSR for the 1994-2014 epoch is characterized by a meridional dipole structure, the positive phase of which is associated with negative rainfall anomaly south of Yangtze River and positive rainfall anomaly north of Yangtze River.

2. In CCSM4 simulation under constant external forcing, the leading mode of ECSR is the triple mode in some 
Fig. 12 The difference of the mean state SST between the dipole and triple epochs for the observation (a) and CCSM4 simulation (b). The warming trend is removed in the observation by subtracting the simultaneous tropical averaged SST over $30^{\circ} \mathrm{S}-30^{\circ} \mathrm{N}$

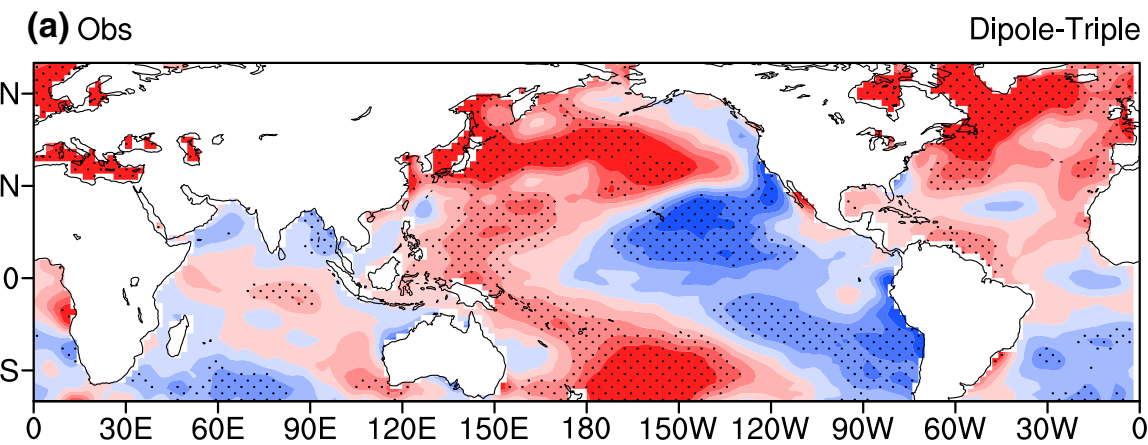

(b) CCSM4

Dipole-Triple

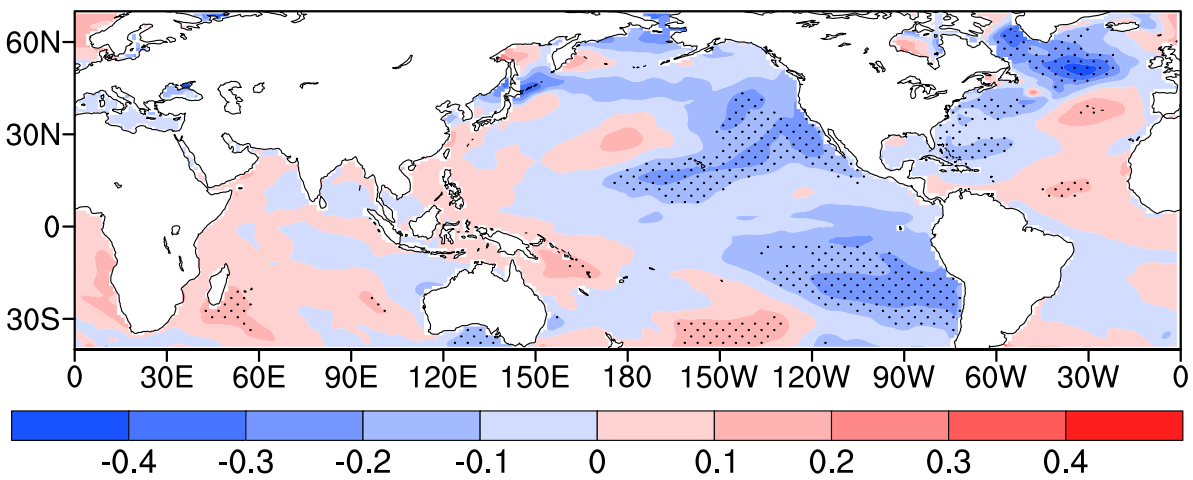

decades but is the dipole mode in some other decades. The leading mode shifts between the triple mode and the dipole mode every several decades. The circulation and SST anomalies associated with the triple and dipole leading modes in CCSM4 are similar to those in the observation. Therefore, both the triple and dipole leading modes and their decadal shifts can be generated by intrinsic variability of the air-sea coupled system.

3. In CAM4 simulation forced by fixed SST annual cycle, the leading mode also shifts between the triple mode and the dipole mode, although only one case of such decadal change is identified in the 200-year simulation. The circulation anomalies associated with the triple and dipole leading modes in CAM4 resemble those in observation and CCSM4. According to the CAM4 simulation, both the triple and the dipole modes and their decadal shifts can also be driven by atmospheric internal dynamics.

4. As agreed by observation, CCSM 4 and CAM 4 simulations, the triple leading mode is associated with enhanced (weakened) WNPSH and southward (northward) shifted EAJ at its positive (negative) phase. A meridional wave pattern along the East Asian coast resembling the PJ/EAP pattern is seen during the epochs with triple leading mode. The dipole leading mode is associated with enhanced (weakened) WNPSH and enhanced (weakened) EAJ at its positive (negative) phase, accompanied by zonal wave train over mid-latitude Eurasian continent.
Many previous studies emphasized the impact of decadal SST signals on the decadal changes of East Asian rainfall. The mean state rainfall of Eastern China experienced a decadal change in the late 1970s, characterized by wetter southern China and drier northern China (Ding et al. 2008, 2009). The Pacific Decadal Oscillation (PDO) was claimed to be responsible for this decadal change (Li et al. 2010). The decadal change in SST mean state also alters the atmospheric mean state and may further alter the response of atmospheric anomalies to SST anomalies (Wu and Wang 2002). As agreed by observation and CCSM4 simulation, the difference of SST between Dipole epochs and Triple epochs is characterized by cold SST anomalies over tropical central-eastern Pacific (Fig. 12), resembling the negative phase of PDO. Therefore, the triple (dipole) mode is more likely to be the leading mode at the positive (negative) phase of PDO in the air-sea coupled system. However, the decadal SST anomalies are not the necessity since the shift between the triple and dipole pattern also exists in CAM4 simulation without air-sea interaction.

Acknowledgments This work was jointly supported by National Basic Research Program of China (2014CB953901), National Natural Science Foundation of China (41505067, 41330423, 41375095 and 41575043), and Strategic Priority Research Program of the Chinese Academy of Sciences (XDA11010403). The CCSM4 pre-industrial run is provided by NCAR via PCMDI (http://pcmdi9.1lnl.gov), and the observational data are provided by NOAA (http://www.esrl.noaa. 
gov/psd/data/). We wish to thank the NOAA, NCAR and PCMDI who provided us observational data and model data.

Open Access This article is distributed under the terms of the Creative Commons Attribution 4.0 International License (http://creativecommons.org/licenses/by/4.0/), which permits unrestricted use, distribution, and reproduction in any medium, provided you give appropriate credit to the original author(s) and the source, provide a link to the Creative Commons license, and indicate if changes were made.

\section{References}

Adler RF, Huffman GJ, Chang A, Ferraro R, Xie PP, Janowiak J, Rudolf B, Schneider U, Curtis S, Bolvin D, Gruber A, Susskind J, Arkin P, Nelkin E (2003) The version-2 global precipitation climatology project (GPCP) monthly precipitation analysis (1979-present). J Hydrometeorol 4(6):1147-1167. doi:10.1175/1525-7541(2003)004<1147:tvgpcp >2.0.co;2

Ai W, Dong W, Zhang P (2008) A downscaling method based on the empirical orthogonal function (EOF) and its application in seasonal prediction. J Trop Meteorol 244:320-326

Chen X, Zhou T (2014) Relative role of tropical SST forcing in the 1990s periodicity change of the Pacific-Japan pattern interannual variability. J Geophys Res Atmos 119(23):13043-13066. doi:10.1002/2014jd022064

Chen W, Kang L, Wang D (2006) The coupling relationship between summer rainfall in China and global sea surface temperature. Clim Environ Res 11(3):259-269. doi:10.3878/j.issn.10069585.2006.03.02 (in Chinese)

Chen J, Wu R, Wen Z (2012) Contribution of south China Sea tropical cyclones to an increase in southern China summer rainfall around 1993. Adv Atmos Sci 29(3):585-598. doi:10.1007/ s00376-011-1181-6

Chen L, Yu Y, Sun D-Z (2013) Cloud and water vapor feedbacks to the El Niño warming: are they still biased in CMIP5 models? J Clim 26(14):4947-4961. doi:10.1175/jcli-d-12-00575.1

Chen Z, Wen Z, Wu R, Lin X, Wang J (2015) Relative importance of tropical SST anomalies in maintaining the Western North Pacific anomalous anticyclone during El Niño to La Niña transition years. Clim Dyn. doi:10.1007/s00382-015-2630-1

Chung P-H, Sui C-H, Li T (2011) Interannual relationships between the tropical sea surface temperature and summertime subtropical anticyclone over the western North Pacific. J Geophys Res Atmos 116:D13111. doi:10.1029/2010jd015554

Day JA, Fung I, Risi C (2015) Coupling of South and East Asian monsoon precipitation in July-August. J Clim 28(11):4330 4356. doi:10.1175/jcli-d-14-00393.1

Ding Y, Wang Z, Sun Y (2008) Inter-decadal variation of the summer precipitation in East China and its association with decreasing Asian summer monsoon. Part I: observed evidences. Int J Climatol 28(9):1139-1161. doi:10.1002/joc.1615

Ding Y, Sun Y, Wang Z, Zhu Y, Song Y (2009) Inter-decadal variation of the summer precipitation in China and its association with decreasing Asian summer monsoon part II: possible causes. Int J Climatol 29(13):1926-1944. doi:10.1002/joc.1759

Du Y, Xie SP, Huang G, Hu KM (2009) Role of air-sea interaction in the long persistence of El Nino-induced North Indian Ocean Warming. J Clim 22(8):2023-2038. doi:10.1175/2008jcli2590.1

Feng J, Chen W, Tam CY, Zhou W (2011) Different impacts of El Nino and El Nino Modoki on China rainfall in the decaying phases. Int J Climatol 31(14):2091-2101. doi:10.1002/joc.2217

Gao H, Jiang W, Li W (2015) Changed relationships between the East Asian summer monsoon circulations and the summer rainfall in eastern China. J Meteorol Res 28(6):1075-1084. doi:10.1007/ s13351-014-4327-5

Gong DY, Ho CH (2002) Shift in the summer rainfall over the Yangtze River valley in the late 1970s. Geophys Res Lett 29(10):1436. doi:10.1029/2001g1014523

Guo L, Highwood EJ, Shaffrey LC, Turner AG (2013) The effect of regional changes in anthropogenic aerosols on rainfall of the East Asian Summer Monsoon. Atmos Chem Phys 13(3):15211534. doi:10.5194/acp-13-1521-2013

Han J, Zhang R (2009) The dipole mode of the summer rainfall over East China during 1958-2001. Adv Atmos Sci 26(4):727-735. doi:10.1007/s00376-009-9014-6

He C, Zhou T (2014) The two interannual variability modes of the Western North Pacific Subtropical High simulated by 28 CMIP5-AMIP models. Clim Dyn 43(9-10):2455-2469. doi:10.1007/s00382-014-2068-x

He C, Zhou T (2015) Responses of the western North Pacific subtropical high to global warming under RCP4.5 and RCP8.5 scenarios projected by 33 CMIP5 models: the dominance of tropical Indian Ocean-tropical Western Pacific SST gradient. J Clim 28(1):365-380. doi:10.1175/jcli-d-13-00494.1

He C, Zhou T, Wu B (2015) The Key Oceanic Regions Responsible for the interannual variability of the Western North Pacific subtropical high and associated mechanisms. J Meteorol Res 29(4):562-575. doi:10.1007/s13351-015-5037-3

Hsu H-H, Lin S-M (2007) Asymmetry of the tripole rainfall pattern during the East Asian summer. J Clim 20(17):4443-4458. doi: $10.1175 /$ jcli4246.1

Huang R, Sun F (1992) Impacts of the tropical western Pacific on the East Asian summer monsoon. J Meteorol Soc Jpn 70(1B):243-256

Huang R, Chen J, Liu Y (2011) Interdecadal variation of the leading modes of summertime precipitation anomalies over Eastern China and its association with water vapor transport over East Asia. Chin J Atmos Sci 35(4):589-606 (In Chinese)

Huang R, Chen J, Wang L, Lin Z (2012) Characteristics, processes, and causes of the spatio-temporal variabilities of the East Asian monsoon system. Adv Atmos Sci 29(5):910-942. doi:10.1007/ s00376-012-2015-x

Huang D-Q, Zhu J, Zhang Y-C, Huang A-N (2014) The different configurations of the East Asian polar front jet and subtropical jet and the associated rainfall anomalies over Eastern China in summer. J Clim 27(21):8205-8220. doi:10.1175/jcli-d-14-00067.1

Jiang D, Tian Z (2013) East Asian monsoon change for the 21st century: results of CMIP3 and CMIP5 models. Chin Sci Bull 58(12):1427-1435. doi:10.1007/s11434-012-5533-0

Kajikawa Y, Wang B (2012) Interdecadal change of the South China sea summer monsoon onset. J Clim 25(9):3207-3218. doi:10.1175/jcli-d-11-00207.1

Kanamitsu M, Ebisuzaki W, Woollen J, Yang SK, Hnilo JJ, Fiorino M, Potter GL (2002) NCEP-DOE AMIP-II reanalysis (R-2). B Am Meteorol Soc 83(11):1631-1643. doi:10.1175/bams-83-11-1631

Krishnamurthy L, Krishnamurthy V (2014) Influence of PDO on South Asian summer monsoon and monsoon-ENSO relation. Clim Dyn 42(9-10):2397-2410. doi:10.1007/s00382-013-1856-Z

Kuang X, Zhang Y (2006) Impact of the position abnormalities of East Asian subtropical westerly jet on summer precipitation in middle-lower reaches of Yangtze River. Plateau Meteorol 25(3):382-389 (In Chinese)

Lau NC, Nath MJ (2003) Atmosphere-ocean variations in the IndoPacific sector during ENSO episodes. J Clim 16(1):3-20. doi:10.1175/1520-0442(2003)016<0003:aoviti>2.0.co;2

Li L, Zhang Y (2014) Effects of different configurations of the East Asian subtropical and polar front jets on precipitation during the Mei-Yu season. J Clim 27(17):6660-6672. doi:10.1175/ jcli-d-14-00021.1 
Li SL, Lu J, Huang G, Hu KM (2008) Tropical Indian Ocean basin warming and East Asian summer monsoon: a multiple AGCM study. J Clim 21(22):6080-6088. doi:10.1175/2008jcli2433.1

Li H, Dai A, Zhou T, Lu J (2010) Responses of East Asian summer monsoon to historical SST and atmospheric forcing during 1950-2000. Clim Dyn 34(4):501-514. doi:10.1007/ s00382-008-0482-7

Li X, Zhou W, Chen D, Li C, Song J (2014) Water vapor transport and moisture budget over Eastern China: remote forcing from the two types of El Niño. J Clim 27(23):8778-8792. doi:10.1175/ jcli-d-14-00049.1

Lu R (2001) Interannual variability of the summertime North Pacific subtropical high and its relation to atmospheric convection over the warm pool. J Meteorol Soc Jpn 79(3):771-783. doi:10.2151/ jmsj.79.771

Lu R (2005) Interannual variation of North China rainfall in rainy season and SSTs in the equatorial eastern Pacific. Chin Sci Bull 50(18):2069-2073. doi:10.1007/bf03322803

Ma Y, Chen W, Wang L (2011) A comparative study of the interannual variation of summer rainfall anomolies between the Huaihe Meiyu season and the Jiangnan Meiyu season and their climate background. Acta Meteorol Sin 69(2):334-343. doi:10.11676/ qxxb2011.028 (In Chinese)

Nitta T (1987) Convective activities in the tropical Western Pacific and their impact on the Northern hemisphere summer circulation. J Meteorol Soc Jpn Ser II 65(3):373-390

Pang Y, Zhu C, Liu K (2014) Analysis of stability of EOF modes in summer rainfall anomalies in China. Chin J Atmos Sci 38(6):1137-1146. doi:10.3878/j.issn.1006-9895.1402.13274 (In Chinese)

Smith TM, Reynolds RW, Peterson TC, Lawrimore J (2008) Improvements to NOAA's historical merged land-ocean surface temperature analysis (1880-2006). J Clim 21(10):2283-2296. doi:10.11 $75 / 2007$ jcli2 100.1

Song F, Zhou T (2014) The climatology and interannual variability of East Asian summer monsoon in CMIP5 coupled models: does air-sea coupling improve the simulations? J Clim 27(23):87618777. doi:10.1175/jcli-d-14-00396.1

Sperber KR, Annamalai H, Kang IS, Kitoh A, Moise A, Turner A, Wang B, Zhou T (2013) The Asian summer monsoon: an intercomparison of CMIP5 vs. CMIP3 simulations of the late 20th century. Clim Dyn 41(9-10):2711-2744. doi:10.1007/ s00382-012-1607-6

Sui CH, Chung PH, Li T (2007) Interannual and interdecadal variability of the summertime western North Pacific subtropical high. Geophys Res Lett 34(11):L11701. doi:10.1029/2006gl029204

Sun B, Wang H (2015) Inter-decadal transition of the leading mode of inter-annual variability of summer rainfall in East China and its associated atmospheric water vapor transport. Clim Dyn 44(910):2703-2722. doi:10.1007/s00382-014-2251-0
Taylor KE, Stouffer RJ, Meehl GA (2012) An overview of CMIP5 and the experiment design. B Am Meteorol Soc 93(4):485-498. doi:10.1175/bams-d-11-00094.1

Wang B, Xiang B, Lee J-Y (2013) Subtropical high predictability establishes a promising way for monsoon and tropical storm predictions. Proc Natl Acad Sci 110(8):2718-2722. doi:10.1073/ pnas. 1214626110

Wu R (2002) A mid-latitude Asian circulation anomaly pattern in boreal summer and its connection with the Indian and East Asian summer monsoons. Int J Climatol 22(15):1879-1895. doi: $10.1002 /$ joc. 845

Wu R, Wang B (2002) A contrast of the East Asian summer monsoonENSO relationship between 1962-1977 and 1978-1993*. J Clim 15(22):3266-3279. doi:10.1175/1520-0442(2002)015<3266:aco tea $>2.0 . c 0 ; 2$

Wu B, Zhou TJ (2008) Oceanic origin of the interannual and interdecadal variability of the summertime western Pacific subtropical high. Geophys Res Lett 35(13):L13701. doi:10.1029/200 $8 \mathrm{~g} 1034584$

Wu R, Hu Z-Z, Kirtman BP (2003) Evolution of ENSO-related rainfall anomalies in East Asia. J Clim 16(22):3742-3758. doi:10.1175/1520-0442(2003)016<3742:eoerai $>2.0 . c 0 ; 2$

Wu RG, Wen ZP, Yang S, Li YQ (2010a) An interdecadal change in Southern China summer rainfall around 1992/1993. J Clim 23(9):2389-2403. doi:10.1175/2009jcli3336.1

Wu B, Li T, Zhou TJ (2010b) Relative contributions of the Indian Ocean and local SST anomalies to the maintenance of the Western North Pacific anomalous anticyclone during the El Nino decaying summer. J Clim 23(11):2974-2986. doi:10.1175/2010 jcli3300.1

Wu B, Zhou T, Li T (2016) Impacts of the Pacific-Japan and circumglobal teleconnection patterns on interdecadal variability of the East Asian summer monsoon. J Clim. doi:10.1175/ jcli-d-15-0105.1

Xie SP, Hu KM, Hafner J, Tokinaga H, Du Y, Huang G, Sampe T (2009) Indian Ocean capacitor effect on Indo-Western Pacific climate during the summer following El Nino. J Clim 22(3):730 747. doi: $10.1175 / 2008$ jcli2544.1

Ye H, Lu R (2012) Dominant patterns of summer rainfall anomalies in East China during 1951-2006. Adv Atmos Sci 29(4):695-704. doi:10.1007/s00376-012-1153-5

Zhao P, Yang S, Wang H, Zhang Q (2011) Interdecadal relationships between the Asian-Pacific Oscillation and summer climate anomalies over Asia, North Pacific, and North America during a recent 100 years. J Clim 24(18):4793-4799. doi:10.1175/ jcli-d-11-00054.1

Zhou TJ, Yu RC (2005) Atmospheric water vapor transport associated with typical anomalous summer rainfall patterns in China. J Geophys Res Atmos 110:D08104. doi:10.1029/2004jd005413 